Marine Pollution Bulletin

April 2015, Volume 93, Issues 1-2, Pages 1-4

http://dx.doi.org/10.1016/..marpolbul.2015.02.021

http://archimer.ifremer.fr/doc/00254/36550/

(c) 2015 Elsevier Ltd. All rights reserved.

\title{
What did we learn from PEGASEAS forum "Science and Governance of the Channel Marine Ecosystem"?
}

\author{
Evariste Emmanuelle ${ }^{1,2}$, Claquin Pascal ${ }^{1,2}$, Robin Jean-Pierre ${ }^{1,2}$, Auber Arnaud ${ }^{3}$, Mcquatters-Gollop \\ Abigail $^{4}$, Fletcher Stephen ${ }^{5,6}$, Glegg Gillian ${ }^{5}$, Dauvin Jean-Claude ${ }^{1,7,{ }^{*}}$
}

${ }^{1}$ Normandie Université, Université de Caen Basse-Normandie, F-14032 Caen, France

2 UMR BOREA, CNRS-7208, IRD-207, MNHN, UPMC, UniCaen, Esplanade de la paix, F-14032 Caen, France

3 IFREMER, Laboratoire Ressource Halieutiques, 150 quai Gambetta, BP699, 62321 Boulogne-surMer, France

${ }^{4}$ Sir Alister Hardy Foundation for Ocean Science, The Laboratory, Citadel Hill, Plymouth PL1 2PB, UK

${ }^{5}$ Centre for Marine and Coastal Policy Research, Plymouth University, Drake Circus, Plymouth PL4 8AA, UK

${ }^{6}$ United Nations Environment Programme - World Conservation Monitoring Centre, Huntington Road, Cambridge CB3 ODL, UK

${ }^{7}$ Université de Caen Basse Normandie, Laboratoire Morphodynamique Continentale et Côtière, UMR CNRS 6143 M2C, Caen, France

* Corresponding author : Jean-Claude Dauvin, email address : jean-claude.dauvin@unicaen.fr

\begin{abstract}
:
As one of the busiest marine ecosystems in the world, the English Channel is subjected to strong pressures due to the human activities occurring within it. Effective governance is required to improve the combined management of different activities and so secure the benefits provided by the Channel ecosystem. In July 2014, a Cross-Channel Forum, entitled "Science and Governance of the Channel Marine Ecosystem", was held in Caen (France) as part of the INTERREG project "Promoting Effective Governance of the Channel Ecosystem" (PEGASEAS). Here we use outputs from the Forum as a framework for providing Channel-specific advice and recommendations on marine governance themes, including the identification of knowledge gaps, which may form the foundation of future projects for the next INTERREG project call (2015-2020).
\end{abstract}

Keywords : English Channel, Governance, INTERREG programme, Cross-Channel Forum 


\section{Introduction}

For centuries, the English Channel ("la Manche" in French) has been subjected to intense human influence including tourism and leisure, international ports and freight, and the exploitation of living and non-living resources (Carpentier et al., 2005; Dauvin, 2012). It is among the most impacted marine ecosystems in the word due to cumulative effects of human pressures (Halpern et al., 2008). The Channel represents one of the world's busiest shipping lanes, connecting the main ports of North-West Europe to the rest of the world, and used by hundreds of vessels every day. The Channel also contains diverse and abundant living marine resources and thus makes this maritime sector economically important for local and international fisheries that are targeting species threatened by over-exploitation and environmental change. Today, the Channel therefore represents considerable economic potential but its users often have conflicting interests and inadequate governance (Carpentier et al., 2005). The Channel is separated into several international regions (French, English and Belgium), which have different priorities concerning marine ecosystem conservation and management and which threaten the sustainability of the Channel marine ecosystem (Dauvin, 2012; Skinner et al., 2014).

In 2013, the EU's INTERREG programme funded several 'capitalisation' projects, which focused on adding value to previous INTERREG IVA projects in the Channel, by extracting the most important information that could be used to achieve sustainable development in the Channel. The "Promoting Effective Governance of the Channel Ecosystem" project (PEGASEAS) aimed to promote improved governance of the Channel marine environment by capitalising on several INTERREG IVA projects.

During the PEGASEAS project, three Cross-Channel forums were held concerning the theme of Channel governance which was defined in the broadest sense as the sum of all the processes, organisations, institutions and instruments with an influence over how the marine ecosystem of the English Channel is used and managed. As there is no official Channel governance body or association, the forums provided a unique opportunity for decision-makers, scientists, managers and stakeholders to discuss how to improve the governance of the Channel marine ecosystem through linking the environmental and socio-economic sciences. These forums followed four Cross-Channel forums organized by the INTERREG project CAMIS ("Channel Arc Manche Integrated Strategy") (CAMIS, 2013). Each Forum provided the opportunity for actors on both sides of the Channel to meet and exchange views on methods to improve the management of the Channel's marine ecosystem. While the first and last PEGASEAS forums 
had a wide remit around governance needs, the second forum focussed specifically on the exchange of best practices and methods between scientists and policy-makers and stakeholders.

This editorial synthesises the outputs arising from the second PEGASEAS CrossChannel forum 'Science and Governance of the Channel Marine Ecosystem', held in July 2014 at the University of Caen Basse-Normandie, and extracts key messages arising from the forum to apply to future governance. During this event, scientists and stakeholders discussed scientific Channel-relevant research focusing on integrating marine science into the governance of the Channel ecosystem. It provided an opportunity for scientists to present their research in the context of Channel governance and to contribute to a trans-disciplinary analysis of the Channel marine ecosystem. It stimulated discussions between a wide variety of stakeholders (i.e. scientists, industry, experts and policy makers) about the Channel's marine ecosystem and how current science can be applied to support the governance of the Channel. The forum clearly highlighted important knowledge gaps and suggestions for future areas of research, enabling the formulation of recommendations for upcoming projects, for example those in the next INTERREG project call.

\section{Outputs from the Cross-Channel Forum 'Science and Governance of the Channel Marine Ecosystem' organized by the PEGASEAS project}

The PEGASEAS project and the Cross-Channel forum

PEGASEAS explored a range of themes, from conservation of biodiversity to transboundary cooperation of political bodies to challenges for marine spatial planning in the Channel (Petit and Carpenter, 2014). Through 19 oral presentations and 30 posters produced by scientists and stakeholders, the 150 participants of the Caen Forum had the opportunity to understand and explore important challenges and issues for the Channel marine ecosystem and its governance (Evariste et al., 2014). The forum facilitated the discussion of interdisciplinary themes, previously identified as relevant to aspects of improving Channel governance (Petit and Carpenter, 2014), through a series of workshops which were comprised of scientists, stakeholders and decisionmakers from both sides of the Channel. The relationships and pathways of influence between the themes, as well as the roles of different regional actors, were then articulated, resulting in a clearer understanding of the complex and interdisciplinary structure of Channel governance (Figure 1). The themes of the workshops, which are represented in the boxes in Figure 1, are linked to each other due to the influence and impact they have. For example, scientific projects can produce 
long-term time-series data obtained from the ecosystem which may be shared by partners allowing the production of models and indicators. These outputs could be used to improve the ecosystem conservation.

The outputs of the workshops, and their relevance to Channel governance, are summarised in the following sections. The cross-Channel forum may be thought of as a case study facilitating improved communication between different actors to address issues that are not within the remit of any single governance body and which there is no alternative forum for debate.

\section{Interdisciplinary approach}

A clear need to strengthen relationships between the different actors (scientists, practitioners, stakeholders) working on the Channel and its governance emerged from the Forum workshops (Evariste et al., 2014). Interdisciplinary projects, such as those funded by INTERREG, facilitate interactions between scientists, stakeholders and decision makers. However, during a project's development stage appropriate scientific and governance partners must be identified in order to ensure project effectiveness. Long-term existing collaborations between scientists and stakeholders, including decision makers, where partners know and trust each other, enable the development of a strong network, while developing new relationships is more challenging. However, it is also important to build new collaborations as they can bring fresh perspectives, new partnerships, and new methods and facilities.

When considering a complex system such as the Channel in which social, economic and ecological elements are closely linked projects are much more likely to be successful if partners work together rather than in isolation. A multi-disciplinary, and if possible a trans-disciplinary, approach within a project will decidedly allow a more realistic view of social, economical and environmental issues, which are by essence extremely complex and interconnected.

INTERREG requires involvement of partners from different countries; however, it seems that trans-boundary scientific work is historically uncommon in these projects. For example, of the 38 scientific peer-reviewed papers published from INTERREG IVA projects, only $21 \%$ contain laboratories from both sides of the Channel (PEGASEAS, 2014). Where trans-boundary collaboration was successful, such as with the VALMER project, success was attributed to the understanding of common goals (Evariste et al., 2014). There is a clear need for better integration between project partners to produce results and outcomes which are integrated and trans-boundary. One recommendation would be, for example, to involve partners from both 
sides of the Channel in each project action to facilitate joint working, i.e. French researchers working on English sites and conversely UK researchers working on French sites. Another recommendation would be that $\mathrm{PhD}$ students should be supervised by partners from both sides of the Channel, allowing the development of strong relationships between partners.

\section{Communication}

Forums, such as the one held in Caen, provide an opportunity to introduce possible partners and facilitate discussion of different potential projects. Forums also enable the sharing and exchange of different and well-developed practices and facilitate discussions with reference to multiple marine sectors of interest. Decision-makers and stakeholders showed a real interest in the continuation of this type of forum in the future. One of the key recurring themes taken from the forum concerned the importance of effective communication between partners. Communication is often missing from projects, despite its importance, because, for example, scientists do not take often the time to explain their findings in a way which is easy for nonscientists to understand. They often use jargon and find it necessary to justify their conclusions with numerous statistics that lead to complicated presentations. In addition, the semantics of scientists, stakeholders and politicians are different. There is a need to include in projects people that have a communication role. It would also be interesting to include in the next INTERREG $\mathrm{V}$ programme a project focusing on communication that could work closely with other contemporaneous projects and help them to highlight project advancement and results to nonscientists such as stakeholders and the public (Evariste et al., 2014). This project could be focusing on improving the communication between scientists and stakeholders in the Channel area.

\section{Science within governance}

To improve the governance of the Channel, the participants of the forum emphasised the discussions on the need for institutions and countries to standardise methods and protocols to collect and manage data. Such approaches are necessary for comparison of data over time and space, providing appropriate information and evidence for the decision-making process. Robust long-term time-series are crucial tools for identifying and monitoring ecosystem change and informing management decisions. Information and data obtained during projects should be shared and visible to the actors that could use them for improving governance. In addition, the 
development of tools for decision-makers was discussed, and there is a need for scientists to develop tools (i.e. statistical models) that are usable by a wide range of non-scientists.

\section{Governance}

To improve Channel governance, it would be useful to look at other seas and the policies they use for their governance. For example, the Barcelona Convention focusing on the Mediterranean Sea and OSPAR on the Atlantic contains some policies and governance methods that could be used for the Channel. Discussions held during the forum indicated that often the spatial scale (i.e. local, regional, and national) dictates which issues are a priority in a particular situation and how they can be most readily solved. Therefore it was suggested that the first step towards solving a Channel governance issue is to identify key issues and then choose which scale is most appropriate to deal with them. An example of this can be found in the implementation of the Good Environmental Status (GES) of Marine Strategy Framework Directive in commercial fishery resources where various scales are applied. Descriptor 3 GES (i.e. "commercial fish and shellfish") involves ensuring that commercial fish and shellfish stocks are harvested sustainably. In the Channel, most shared resources are managed at the EU level, whereas local exploitation like scallop dredging in French bays is managed at the national or local level (Portail CHARM III - INTERREG IV, 2012). There are still gaps and shared species like Cephalopods that are not managed at all, although fisheries scientists already share their expertise in the assessment of these stocks (Gras et al., 2014). There are new strategies for maritime space planning such as the Directive 2014/89/EU of the European Parliament and of the Council of 23 July 2014 establishing a framework for maritime spatial planning. This calls for cooperation between EU member states to ensure 'coherent and coordinated across the marine region concerned' making clear that this would operate at a large scale. However, for the development of renewable marine energies, the French government has decided to delimitate zones where wind farms can be built and the UK has also selected suitable sites for wind farms without detailed cross border discussions concerning their likely cumulative impacts.

Supporting governance and cooperation at the scale of the Channel is therefore necessary to meet the specific needs of this shared sea. The implementation of joint governance actions at the Channel scale, whereby the Channel is recognised as a single region independent of the North Sea in its functioning, is crucial. The PEGASEAS project and its cross-Channel forums showed that it is possible to look at managing the Channel as a single space; however, we need to 
continue to support trans-boundary interactions in order to make a distinct cultural change towards management as a common sea.

\section{Conclusion}

There is a strong demand from both the scientific and stakeholder communities to improve their collaborative relationship; appropriate communication is the key to achieving this. Additional efforts should be focussed on improving communication, particularly during events which include non-scientists and the public. The forum held in Caen was successful as over 150 participants came from both sides of the Channel and exchanged their ideas and work, including the discussion of future collaborative projects.

The governance of the Channel is complex as local, regional, national, European and international policies and agreements have to be taken into account. Over the past 20 years, new maritime and coastal policies and legislation have been put in place to face the challenges of the marine environment and to maximise opportunities. Multi-disciplinary and cross-sectorial projects and integrated approaches are essential to improve Channel management and governance. In addition, there is a need to work together recognising the Channel as a single system and not just as distinct country regions.

PEGASEAS and the cross-Channel forums highlighted contrasting visions for Channel management between European and regional political bodies and the French and British states. Regional authorities have developed an extraordinarily enthusiastic cooperation between both sides of the Channel during the past ten years, as evidenced in the degree of trans-boundary cooperation through the INTERREG IVA projects; however, the actual approach of France and the United Kingdom is to further scientific research and to propose future political actions, including targets and indicators of Good Environmental Status, independently. So today, concurrently, we have two separate national visions of the Channel as well as a desire to manage the Channel as one unique space. There is therefore a real gap between the desire to have a transboundary approach and the disparate state positions that still remain in national politics. The lack of international, top-down co-ordination has greatly reduced the effectiveness of the implementation of the European strategies, despite the need, recognized by local and regional scientists and stakeholders, to have a single vision of the functioning and the future of the Channel. 


\section{Acknowledgements}

We would like to thanks INTERREG IVA France (Channel) England for the funding of the PEGASEAS project that funded the Forum held in Caen and also all the PEGASEAS partners and forum participants without whom it would not have been possible to have any output.

\section{References}

CAMIS, 2013. Stratégie maritime intégrée pour l'espace Manche: un plan pour l'action. 64 pp. https://camis.arcmanche.eu/stock/files/user4/13_247_Camis_doc_strategie_maritime_FR_ BD_2.pdf

Carpentier, A., Vaz, S., Martin, C. S., Coppin, F., Dauvin, J-C., Desroy, N., Dewarumez, J-M. 2005. Eastern Channel Habitat Atlas for Marine Resource Management (CHARM). Atlas des Habitats des Ressources Marines de la Manche Orientale, INTERREG IIIA. 225 pp

Dauvin, J.C., 2012. Are the Eastern and Western basins of the English Channel two separate ecosystems? Marine Pollution Bulletin 64, 463-471.

Evariste, E., Dauvin, J.-C., Claquin, P., Auber, A., Winder, A., Thenail, B., Fletcher, S., Robin, J.P. (eds), 2014 Trans-Channel forum proceedings "Science and governance of the Channel marine ecosystem". INTERREG IVA Programme, Université de Caen Basse-Normandie, Caen, France, 160 pp.

Halpern, B.S., Walbridge, S., Selkoe, K.A., Kappel, C.V., Micheli, F., D’Agrosa, C., Bruno, J.F., Casey, K.S., Ebert, C., Fox, H.E., Fujita, R., Heinemann, D., Lenihan, H.S., Madin, E.M.P., Perry, M.T., Selig, E.R., Spalding, M., Steneck, R., Watson, R., 2008. A Global Map of Human Impact on Marine Ecosystems. Science 319, 948-952.

PEGASEAS, 2014. Channel INTERREG IVA project marine governance matrix. www.pegaseas.eu.

Petit, L., Carpenter, A. (eds), 2014. Towards better governance of the Channel ecosystem. Report from the Promoting Effective Governance of the Channel Ecosystem Project; www.pegaseas.eu.

Portail CHARM III - INTERREG IV. (C) 2012. Atlas des pêcheries de Manche, Channel fisheries Atlas. Engelhard G., Vignot C., Leblond E., Lesueur M., Guitton J. http://charm-project.org/fr/outils/atlas-des-pecheries/atlas-des-pêcheriesoutils. 
Skinner, J., Bailly, D., Le Coz, M., Dodds, W., Fletcher, S., Glegg, G., Glenn, H., Herry, L., Molfese, J., Sewell, J., McQuatters-Gollop, A. 2014 Pathways for effective governance of the English Channel. Sir Alister Hardy Foundation for Ocean Science, Plymouth, UK, 50pp. 
Figure 1: Forum workshop themes and pathways of influence. The workshop themes are in the boxes while the arrows represent the influence that each component/theme has over another one.

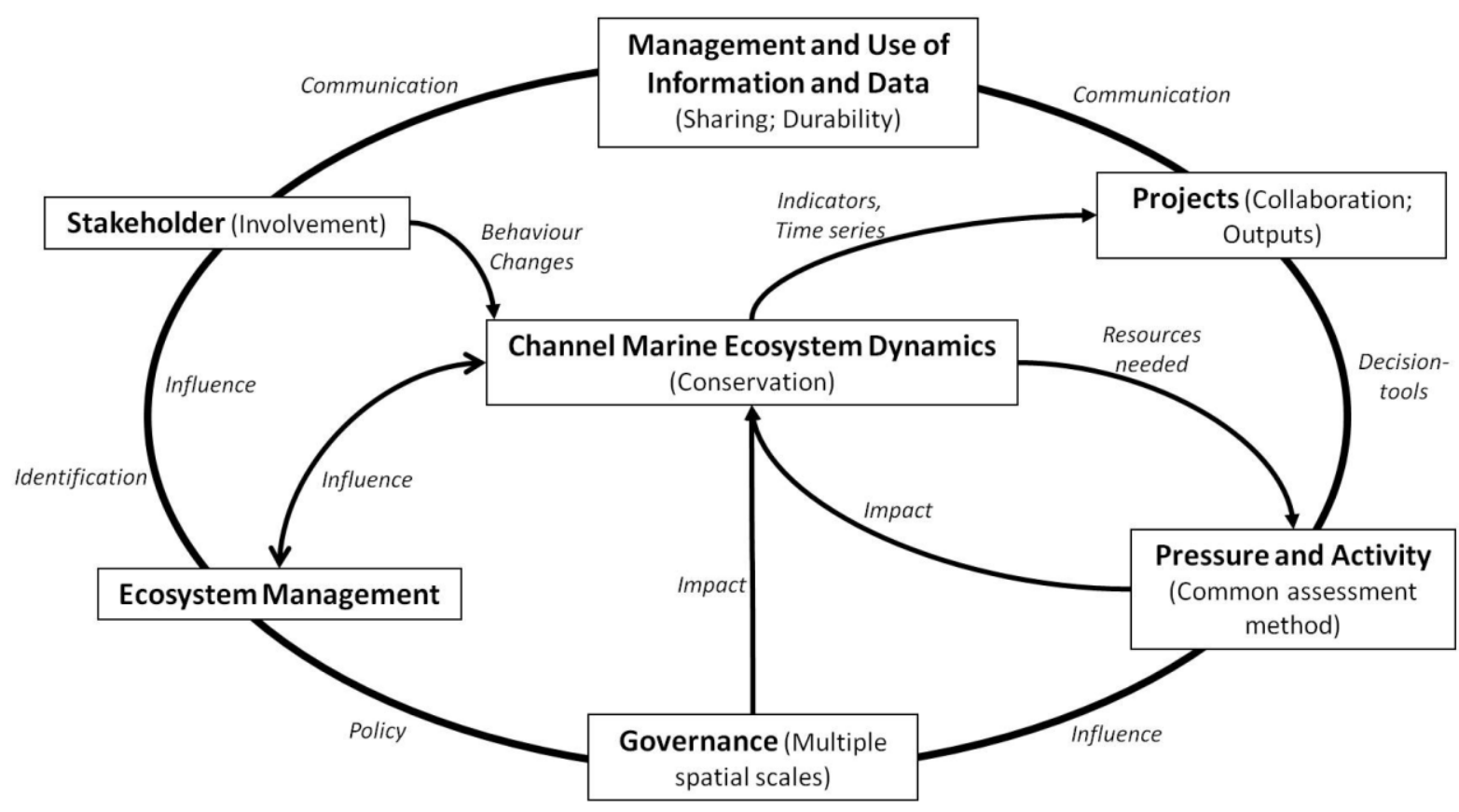

